\title{
Synchrony of peak-rate years suggests challenges to sustainable development: a response to O'Sullivan (2015)
}

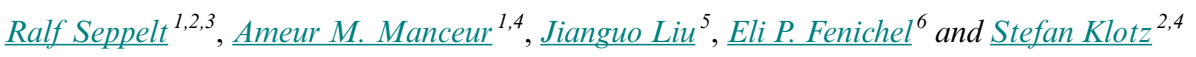

Key Words: limits to growth; peak-rate year; synchrony

Resource use is key for sustainability. In the past, analyses of resource use often focused on one or a few resources. When analyzing the use of multiple resources simultaneously, we found synchrony of peak-rate years underpinned by long and up-to-date time series (Seppelt et al. 2014). This is clearly in line with and underpins the recent analysis of anthropogenic signatures in geological records leading to the definition of the Anthropocene epoch (Lewis and Maslin 2015).

However, O'Sullivan (2015) argues that our results "distract from real planetary limits." Her argument misinterprets our main message. The misinterpretation perhaps originates from a misunderstanding of the underlying methodology with respect to the conceptual framework and the statistical analysis while ignoring the uncertainty analysis presented in the original paper. Although some media outlets may have unfortunately sensationalized some of our results, like they may have done on many other scientific reports, we hope to draw readers to our original paper. Below we respond to O'Sullivan (2015) in more detail.

To adequately analyze rates of resource use, we developed a conceptual framework including a consistent statistical procedure. Renewable and nonrenewables were treated differently because they differ in terms of regrowth.

In simple terms, "sustainability" for harvesting renewables can be seen because the harvested amount is not more than the amount regrown in a specific time frame. In this case a time series of resource use would show a plateau, similar to the data of fish caught or peat in our analysis. Today, for most of the resources humans use such a plateau is not reached. The peak-rate year, i.e., the year of fastest increase of production, refers to the inflection point of the harvesting or production curve and thus provides an early warning signal that possible plateauing might come in the near future.

For nonrenewable resources there is no regrowth, at least not on human time scales. For analyzing these time series in the same way, we used the cumulative amount, taking into account that reaching a plateau equals the full depletion of this resource. One might argue that this case substantially differs from the plateauing of renewables, as the nonrenewable resource is depleted, while the renewables can still be harvested. However, our analysis did not discuss how a world in this case might look. We chose to offer unbiased, data-based statistics to provide early warning indicators.

We thus present a consistent methodology and statistics for analyzing time series of resource use for renewables as well as nonrenewables. This conceptual framework does not make use of a mathematical model requiring "symmetry" because we do not use a logistic model but take a nonparametric approach, which does not require stationarity. Figure 1 in Seppelt et al. (2014) is an example, simplified, not what we did exactly. This distinguishes the study from those on peak oil for instance (Gallagher 2011), providing the opportunity to capture events such as shocks or innovations, i.e., nonstationarity of the processes.

Various aspects of O'Sullivan's response refer to the statistical procedures used for identifying peak-rate years (Seppelt et al. 2014, see Methods and Appendix 1). Because time series data of resource production are not perfectly continuous, we smoothed the time series in a bootstrap procedure. This statistically removes "blips" and considers that there is no perfectly smooth development and that bumps or spikes might change the outcome.

Time series used are quite long, which shows that O'Sullivan's (2015) "paycheck" example does not apply for the data at hand. The bootstrapping approach furthermore provides the uncertainty interval of the estimated peak-rate year. The uncertainty suggests that for a few resources the final peak-rate year might be later than estimated. These are cassava, cotton, soybeans, sugar cane, wheat, and wood. These resources demonstrate a peak-rate year but the 97.5 th percentile year equals the last year of the time series indicating that the upper uncertainty interval is truncated (Seppelt et al. 2014, Table 3). Of course, more future work could be done to develop formal statistical tests that suggest how many years of data must exist following a peak to determine that the peak is meaningful.

Figure 4 in Seppelt et al. (2014) uses 16 independent time series (not all the time series from Table 3). For each of the 5000 samples, there may be only one mode in the distribution of peaks, but the mode did not fall on 2006 by chance (thus there is an evident synchrony).

Finally, O'Sullivan (2015) gave some counter examples for our analysis, for which peak-rate years might be questionable, namely dairy, land use, fossil fuels, and population. For dairy, O'Sullivan

${ }^{1}$ UFZ - Helmholtz Centre for Environmental Research, Department Computational Landscape Ecology, Germany, ${ }^{2}$ iDiv - German Centre for Integrative Biodiversity Research, Germany, ${ }^{3}$ Institute of Geoscience \& Geography, Martin-Luther-University Halle-Wittenberg, Germany, ${ }^{4}$ UFZ Helmholtz Centre for Environmental Research, Department Community Ecology, Germany, ${ }^{5}$ Center for Systems Integration and Sustainability, Michigan State University, USA, ${ }^{6}$ Yale School of Forestry and Environmental Studies, Yale University, USA 
(2015) misses the fact that this peak-rate year was estimated with a considerably large uncertainty from 1964 to 2004, which is due to the variability of the data. This uncertainty can be visualized in Figure 3 in Seppelt et al. (2014), designed specifically to summarize a vast amount of data along with uncertainty about inference.

For conversion to agricultural land we identified a peak-rate year in 1950 with an uncertainty interval 1920-1960. Conversion to cropland still continues, but with a slower pace. There is no selfcontradiction in these findings.

Surprisingly, peak-rate years were not identified for nonrenewable resources. Peak years of fossil fuels are still debated in recent literature (Bardi 2009, Gallagher 2011). Because a high proportion of today's agricultural production is based on fossil fuels, this fact provides evidence that reduced intensity, i.e., energy input, of agricultural production is not a cause for peak-rate years.

Maximum growth of human population was in 1989 with a comparable small interval of uncertainty. Of course human population is growing further, but demographic change occurred in most parts of the world, and plays out in global aggregate statistics. Growth is declining because of access to birth control, improved sanitary situation, reduced child mortality, woman in labor force, improved health care, and social security (Bongaarts 2009, Lutz and K.C. 2010).

Our database (published with the paper) is based on accessible data, mostly from the Food and Agriculture Organization of the United Nations (FAO 2013). This limits the analysis to official statistics and neglects subsistence farming, which is a major pillar of food security (Tscharntke et al. 2012). Opportunities exist for closing the "yield gap" (Mueller et al. 2012) for certain regions in the world (Václavík et al. 2013). In general, however, we confirm recent findings, which estimate a possible increase of yields by $45 \%$ to $70 \%$. The increase, however, comes with enormous challenges on water availability, nutrient supply, and impacted ecosystem functions and biodiversity (Mueller et al. 2012). These feedbacks are not captured and were discussed (Seppelt et al. 2014)

Measuring sustainability requires a quantitative interdisciplinary approach that can formally describe and quantify scarcity rigorously and systematically. We took a step in this direction, and hope that future work will develop a more comprehensive framework that integrates physical and social measures and confront these with data (Liu et al. 2015).

O'Sullivan (2015) suggests that our paper distracts from real upcoming challenges. However, synchrony of resource use increases challenges to sustainability. Because resources are not consumed independently, options for substitution are limited. Although the paper can be read in the context on the ongoing planetary boundary debate (Steffen et al. 2015), and biophysical considerations provide evidence for limits to further growth of renewable resources, we discuss these issues cautiously in our paper for good reason. To truly assess scarcity, rigorous shadow price estimates are required, and methodology for doing that was only recently developed and remains in its infancy (Fenichel and Abbott 2014).
Developing solutions for future sustainable development thus requires careful consideration of options for innovation, changes of preferences, opportunities of substitutions, and the correlations amongst them. Our paper aimed at discussing these issues and not oversimplifying facts on possible planetary limits.

Responses to this article can be read online at: http://www.ecologyandsociety.org/issues/responses. php/7633

\section{LITERATURE CITED}

Bardi, U. 2009. Peak oil: the four stages of a new idea. Energy 34 (3):323-326. http://dx.doi.org/10.1016/j.energy.2008.08.015

Bongaarts, J. 2009. Human population growth and the demographic transition. Philosophical Transactions of the Royal Society of London. Series B, Biological Sciences 364 (1532):2985-2990. http://dx.doi.org/10.1098/rstb.2009.0137

Fenichel, E. P., and J. K. Abbott. 2014. Natural capital from metaphor to measurement. Journal of the Association of Environmental and Resource Economists 1:1-27. http://dx.doi. org/10.1086/676034

Food and Agriculture Organization of the United Nations (FAO). 2013. FAOSTAT. Food and Agriculture Organization of the United Nations, Statistics Division. [online] URL: http://faostat3. fao.org/download/FB/CC/E

Gallagher, B. 2011. Peak oil analyzed with a logistic function and idealized Hubbert curve. Energy Policy 39(2):790-802. http://dx. doi.org/10.1016/j.enpol.2010.10.053

Lewis, S. L., and M. A. Maslin. 2015. Defining the Anthropocene. Nature 519(7542):171-180. http://dx.doi.org/10.1038/nature14258

Liu, J., H. Mooney, V. Hull, S. J. Davis, J. Gaskell, T. Hertel, J. Lubchenco, K. C. Seto, P. Gleick, C. Kremen, and S. Li. 2015. Systems integration for global sustainability. Science 347:1258832. http://dx.doi.org/10.1126/science.1258832

Lutz, W., and S. K.C. 2010. Dimensions of global population projections: what do we know about future population trends and structures? Philosophical Transactions of the Royal Society of London. Series B, Biological Sciences 365(1554):2779-2791. http:// dx.doi.org/10.1098/rstb.2010.0133

Mueller, N. D., J. S. Gerber, M. Johnston, D. K. Ray, N. Ramankutty, and J. A. Foley. 2012. Closing yield gaps through nutrient and water management. Nature 490(7419):254-257. http://dx.doi.org/10.1038/nature11420

O'Sullivan, J. 2015. Resource use peak dates distract from real planetary limits. Ecology and Society 20(2):32. http://dx.doi. org/10.5751/ES-07579-200232

Seppelt, R., A. M. Manceur, J. Liu, E. P. Fenichel, and S. Klotz. 2014. Synchronized peak-rate years of global resources use. Ecology and Society 19(4): 50. http://dx.doi.org/10.5751/ es-07039-190450 
Steffen, W., K. Richardson, J. Rockström, S. E. Cornell, I. Fetzer, E. M. Bennett, R. Biggs, S. R. Carpenter, W. de Vries, C. A. de Wit, C. Folke, D. Gerten, J. Heinke, G. M. Mace, L. M. Persson, V. Ramanathan, B. Reyers, and S. Sörlin. 2015. Planetary Boundaries: guiding human development on a changing planet. Science 347(6223). http://dx.doi.org/10.1126/science.1259855

Tscharntke, T., Y. Clough, T. C. Wanger, L. Jackson, I. Motzke, I. Perfecto, J. Vandermeer, and A. Whitbread. 2012. Global food security, biodiversity conservation and the future of agricultural intensification. Biological Conservation 151(1):53-59. http://dx. doi.org/10.1016/j.biocon.2012.01.068

Václavík, T., S. Lautenbach, T. Kuemmerle, and R. Seppelt. 2013. Mapping global land system archetypes. Global Environmental Change 23:1637-1647. http://dx.doi.org/10.1016/j.gloenvcha.2013.09.004 